\title{
The relationship between adolescent risk perception and emotions during the COVID-19: a short-term longitudinal study
}

\author{
Tong-tong Xin ${ }^{1} \cdot$ Xiu-jun $\mathrm{Li}^{1} \cdot$ Lei-Shen $^{1} \cdot$ Wen-yu Ding ${ }^{1} \cdot$ Wei-Liu $^{1} \cdot$ Ning-Chen ${ }^{1}$
}

Accepted: 31 January 2022

(c) The Author(s), under exclusive licence to Springer Science+Business Media, LLC, part of Springer Nature 2022

\begin{abstract}
This study explores the relationship between adolescents' perceptions of epidemic risk and their emotions through three follow-up surveys during the early stages of the COVID-19 pandemic on February 11th (T1), 18th (T2), and 25th (T3), 2020. Three hundred and four adolescents in different academic stages (junior high middle school, senior high middle school, and university) participated in the online survey, and cross-lag analysis was used to examine the causal relationship between epidemic risk perceptions and positive and negative emotions. The results found that the individual's positive emotions were significantly higher than the negative emotions in T1, T2 and T3. Cross-lag analysis found that for positive emotions, T2 positive emotions could negatively predict $\mathrm{T} 3$ epidemic risk perceptions, and $\mathrm{T} 2$ epidemic risk perceptions could negatively predict the individual's T3 positive emotions. For negative emotions, risk perceptions at T1 could positively predict negative emotions at $\mathrm{T} 2$, and at the same time, negative emotions at $\mathrm{T} 1$ could also positively predict epidemic risk perceptions at $\mathrm{T} 2$. This indicates that during the early stages of the COVID-19 pandemic, there was a causal relationship between the perceptions of epidemic risk and the emotions of adolescents, and this relationship had high stability among groups of different genders and academic stages.
\end{abstract}

Keywords COVID-19 $\cdot$ Epidemic risk perception $\cdot$ Adolescent $\cdot$ Positive emotion $\cdot$ Negative emotion

\section{Introduction}

In December 2019, a new coronavirus (SARS-CoV-2) emerged, sparking an epidemic of acute respiratory syndrome (COVID-19) in humans, centred in Wuhan, China, attracting the notice of regional authorities and rapidly drawing global attention. On Jan 30, 2020, the World Health Organization (WHO) identified COVID-19 as a Public Health Emergency of International Concern "PHEIC (WHO, 2020a, b)". Until now, the COVID-19 epidemic is still widely spread around the world, and both developed and developing countries have not been spared (Wang et al., 2021b; WHO, 2020c). The rapidly spreading COVID-19 has overwhelmed health systems around

Tong-tong Xin and Xiu-jun Li have contributed equally to this work.

Wei-Liu

liuwei@shnu.edu.cn

$\bowtie$ Ning-Chen

chenning@shnu.edu.cn

1 Shanghai Normal University, Shanghai, China the world. It has not only changed people's way of life, but has also affected education, tourism and agriculture, seriously hindering global economic development (Xiong et al., 2020). Because COVID-19 has the characteristics of causing severe infection, being widespread and difficult to prevent or control, and being life-threatening if treatment is not received in time. Therefore, after the outbreak of the epidemic, governments in many countries actively took various measures such as restricting travel, closing public places, and canceling gatherings to prevent and control the epidemic in time (Lee et al., 2021). As the developing country with the earliest concentrated outbreak of the COVID-19 epidemic in the world, as early as the end of January 2020, the government of China actively took various measures to prevent and control the COVID-19. Besides medical treatment and the release of epidemic prevention guidance, the government also asked people to quarantine at home and has instituted school closures or delayed resumption of work to reduce the flow of people.

However, although a series of measures implemented by many governments have effectively curbed the spread of the COVID-19, epidemic information overload and home quarantine have also lead to a rapid increase in psychological 
problems such as fear, anxiety and depression among people all over the world, including China (Martinelli et al., 2020; Riaz et al., 2021; Xiong et al., 2020). The self-awareness of adolescents is constantly developing, and their psychology is not yet fully mature. Facing unexpected risk events such as COVID-19, and lacking the relevant knowledge to deal with epidemic prevention and control, adolescents are more likely to experience negative emotions. Research found that various emotional or behavioral problems affect at least 30 million Chinese children and adolescents under 17 years of age (Zhang, 2006). Further studies showed that the incidence of behavioral and emotional problems was $17.6 \%$ among Chinese school children and adolescents aged 6-16 (Cui, et al., 2020). The epidemic is not over yet, and the risk of contracting the virus remains high. Although studies have found that risk perceptions and negative emotions are significantly positively correlated (Zhong et al., 2020), few studies have explored whether there is a causal relationship between risk perception and emotions. Therefore, this study uses Chinese adolescents as participants and through three followup surveys to explore the relationship between adolescents' perceptions of epidemic risk and their emotions. It has an important role for our understanding of how to improve the mental health of adolescents during the COVID-19 and implementing psychological intervention to young people in similar public health incidents in the future.

\section{Adolescents' risk perception and emotions}

Risk perception refers to the individual's subjective estimate whether the situation have the threat to oneself and their perceived certainty and controllability of the threat situation (Slovic, 2000). Research found that the relationship between risk perception and emotion is particularly important (van der Linden, 2014; Sjöberg, 2007). On the one hand, the risk perception caused by negative emotions not only could decrease the state of the individual's mental health and put the individual into a long-term stress state (Lerner et al., 2010), but also increase the individual's risk behavior level (Hu et al., 2013). On the other hand, positive emotions tend to make individuals ignore unfavorable factors, and reduce risk perception, then make decisions about risk preference (Au et al., 2003; Lin et al., 2006).

Adolescents are in a special period of physical and psychological development, and they are prone to intense mood swings. Even when faced with the same or similar things, adolescents could have a deeper emotional experience than others, and even show more extreme emotions (Arnett, 1999). In addition, due to the immature development of adolescents' own cognitive abilities (Blakemore \& Robbins, 2012) and the lack of risk awareness to unknown events (Pechmann et al., 2005), the relationship between adolescents' risk perception and emotions has aroused great interest among researchers.

A large number of studies have found that the emotions of adolescents could affect their risk perceptions. For example, Haase and Silbereisen, (2011) takes adolescents as participants found that positive emotions produce lower risk perceptions than neutral emotions. Nan (2016) with college students as participants found that fear and anger can positively predict the risk of skin cancer. The above results show that, for adolescents, positive emotions tend to reduce their risk perception, while negative emotions tend to increase risk perception. At the same time, risk perception can also affect emotions. An important factor in reducing risk perception is to increase one's sense of control and self-efficacy. Research has found that self-efficacy can significantly predict an individual's mental health level (Siddiqui, 2015). On the contrary, lack of self-efficacy and sense of control easily produce negative emotions such as anxiety (Frala et al., 2010; Muris, 2002). These results show that there is inter-influence between adolescents' risk perception and emotions. However, during a public health event, what is the relationship between adolescents' risk perceptions and emotions?

\section{The relationship of risk perception and emotion in public health events}

The public's emotional experiences and risk perceptions have always been one of the most important issues for researchers to consider during public health events, such as SARS (Severe Acute Respiratory Syndrome) in 2003, H1N1 in 2009, and Ebola in 2014. A large number of studies have investigated the individual's emotional experience (Blakey et al., 2015; Cowling et al., 2010; Reynolds et al., 2007; Wang et al., 2011), and its relationship with risk perception (Yang \& Chu, 2016) during an epidemic outbreak. Many studies have found that there is a close relationship between individuals' risk perceptions and emotions. For example, Yang and Chu (2016) also found that during the Ebola virus outbreak, people's risk perceptions had a significantly positive correlation with negative emotions such as fear and anxiety. Similarly, during the outbreak of the COVID-19, $\mathrm{Li}$ et al. (2020b) found that there was a significant positive correlation between the severity of the pandemic felt by individuals and their negative emotions. Zhong et al. (2020) also found that significant positive correlation between epidemic risk perception of COVID-19 and depression.

Contrary to the above results, research has also found that positive emotions usually lead to more optimistic risk perceptions (Johnson \& Tversky, 1983). Controllability is an important index of risk perception, and perceived controllability of the epidemic is significantly negatively correlated with negative emotions ( $\mathrm{Li}$ et al., 2020b). Yıldırım and Özaslan (2021) took the medical staff in a Turkish 
hospital as the participants found that, during the COVID19 , perceived controllability was significantly positively correlated with their own subjective well-being. Therefore, we infer that there is a significant negative correlation between risk perception and positive emotions, and risk perception has a significant positive correlation with negative emotions. However, whether there is a causal relationship between emotions and epidemic risk perceptions.

In addition, gender and age are also important factors that affect individual epidemic risk perception and emotions. Indeed, COVID-19 has affected males and females differently, presenting higher fatality rates, a worse prognosis, and higher risk of death in males (Spagnolo et al., 2020). Yet, despite fatality rates, females have a higher prevalence and severity of anxiety, depression, and acute stress symptoms (Liu et al., 2020). The results of age studies show that older people have higher positive emotions when facing COVID19 (Carstensen et al., 2020) and lower infection risk perception (Gerhold, 2020) than young people. For adolescents who are at a critical stage of cognitive development, the COVID-19 epidemic easily leads to various negative emotions and mental disorders. For example, Ren et al. (2021) implemented a study with the sample of 1771 adolescents from junior high middle school, senior high middle school, and university in China and found that symptoms of anxiety and depression were 28.3 and $30.8 \%$ among the participants. Of course, this phenomenon of adolescents showing negative emotions during the COVID-19 epidemic also exists in American college students (Kecojevic et al., 2020). At the same time, the epidemic also makes the majority of adolescents (Yang et al., 2020) and students (Soltan et al., 2020) generate risk perceptions. The above results show that the COVID-19 could damage the mental health of adolescents. However, it remains unclear whether the relationship between risk perception and emotions also could be affected by the adolescents' age and gender.

Based on the above discussion, a large number of studies have explored the emotional experience of adolescents (Ren et al., 2021) at different academic stages, such as children (Shorer \& Leibovich, 2020) and college students (Charles et al., 2021) during the COVID-19 pandemic, and it also includes follow-up studies of Liang et al. (2021) and Li et al. (2021). At the same time, some studies have even found the correlation between the adolescents' emotional experience and their risk perception during the epidemic ( $\mathrm{Li}$ et al., 2020a), but they did not reveal whether there are causal relationships between the risk perception and emotions for the adolescents at different academic stages. Therefore, this study adopts the method of a short-term longitudinal study, taking adolescents at different academic stages as the participants to explore the relationship between individuals' risk perceptions and their emotions during COVID-19.

\section{Method}

\section{Participants}

This study selected 304 adolescent students as participants. In order to make the individual include different academic sages, we invite a junior high middle school, a senior high middle school and two university teachers who have a cooperative relationship with us through social software to recruit students from their school to voluntarily participate in this study. The above schools are all public schools, and all the participants do not include students from Wuhan. Among them, 138 are college students, 87 are senior high middle school students, and 79 are junior high middle school students. Using online data collection, three consecutive surveys were conducted on February 11 (T1), 18 (T2), and 25 (T3) of 2020. There are 129 boys and 175 girls. Except for a few adolescents who were unable to participate in the second or third survey investigations due to poor network connectivity, there were no significant differences in any of the study variables between participants who participated in all three of the study times points and those who did not.

\section{Materials}

Risk perception questionnaire. A self-compiled epidemic risk perception questionnaire was used to measure the epidemic risk perception of the participants. According to the psychometric paradigm (Slovic, 2000), the questionnaire included 6 questions, which were divided into the perception of the degree of harmfulness of the epidemic (I1. Judging from the current situation, the consequences of this epidemic are serious; I2. Judging from the current situation, this epidemic is very harmful; I3. Judging from the current situation, the impact of this epidemic is wide) and the controllability perception of the epidemic (I4. Judging from the current situation, the epidemic is controllable; I5. Judging from the current situation, COVID19 is curable; I6. Judging from the current situation, the government's response to the epidemic is effective). Participants were asked to rate on a 6-point Likert-type scale (1 indicating total disagreement and 6 indicating total agreement) to the all items. In the process of statistical analysis, the controllability perception of the epidemic is scored in reverse and then averaged with the score of the epidemic hazard. The higher the score, the higher the individual's perceived risk regarding the of COVID-19 epidemic. During the first wave investigation of this study, the Cronbach's $\alpha$ coefficients of the hazard and controllability of the epidemic were 0.86 and 0.82 , respectively. 
The result of exploratory factor analysis (EFA) shows that $\mathrm{KMO}=0.72>0.7$, Bartlett's Test of Sphericity approximate chi-squre value $=804.36, p<0.001$, and the load of each factor is greater than 0.8 . A confirmatory factor analysis (CFA) of the questionnaires during the second and third wave shows that the two-factor oblique model has good structural validity (T2: $\chi^{2} / d f=3.69, \mathrm{CFI}=0.98$, $\mathrm{TLI}=0.97, \mathrm{SRMR}=0.05, \mathrm{RMSEA}=0.09 ; \mathrm{T} 3: \chi^{2} / d f=3.48$, $\mathrm{CFI}=0.99, \mathrm{TLI}=0.98, \mathrm{SRMR}=0.03, \mathrm{RMSEA}=0.09) . \mathrm{In}$ the second measurement, the Cronbach's $\alpha$ coefficients of risk perception questionnaire in epidemic harmful perception and epidemic controllability perception were 0.87 and 0.91 . The Cronbach's $\alpha$ coefficients in the third wave 0.91 and 0.93 respectively.

Positive and Negative Affect Schedule (PANAS). The positive and negative emotions of the participants were measured using the Positive and Negative Emotion Scale compiled by Watson et al. (1988). The scale had a total of 18 questions, and was divided into two dimensions. Among them, 9 questions were used to assess positive emotions (i.e., interested), and 9 questions were used to assess negative emotions (e.g., irritability). Responses were provided using a 5-point Likerttype scale $(1=$ not at all, $5=$ extremely $)$. The average score of the two dimensions was counted, respectively. The higher the score, the higher the individual's positive and negative emotions. In this study, the Cronbach's $\alpha$ coefficients of the positive and negative emotion dimensions during the first wave measurement were 0.85 and 0.86 , the second were 0.89 and 0.90 , the third wave were 0.93 and 0.92 , respectively.

\section{Data analyses}

First, the difference between positive and negative emotions was tested in each wave measurement. Second, we used a Pearson's correlation analysis to test the inter-correlation between epidemic risk perception with positive and negative emotions in the three investigations; Third, based on the results of the correlation analysis, a cross-lag analysis was used to examine the causal relationship between epidemic risk perceptions with positive and negative emotions. Finally, a multi-group comparison was used to test cross-lag model difference in terms of gender and academic stages. All models were fitted in Mplus version 7.4.

\section{Result}

\section{Test for the difference between positive and negative emotions in the three measurements}

A paired-sample $t$ test was used to examine the difference between positive and negative emotions at $\mathrm{T} 1, \mathrm{~T} 2$, and $\mathrm{T} 3$. The results showed that the positive emotions were significantly higher than the negative emotions in $\mathrm{T} 1\left(t_{(303)}=13.13\right.$, $p<0.001)$, T2 $\left(t_{(303)}=13.62, p<0.001\right)$, and T3 $\left(t_{(303)}=12.46\right.$, $p<0.001)$. This indicates that adolescents were dominated by positive emotions in the early stage of the COVID-19 pandemic.

\section{Correlation analysis}

From Table 1, it can be seen that the epidemic risk perception is significantly negatively correlated with positive emotions, and it is significantly positively correlated with negative emotions, which satisfies the hypothesis of the cross-lag analysis.

\section{Cross-lag analysis}

\section{Cross-lag analysis of epidemic risk perception with positive and negative emotions}

Based on the correlation analysis, the cross-lag model was constructed to examine the interaction between the adolescent students' risk perceptions with positive emotions (Fig. 1) and negative emotions (Fig. 2) in the three measurements. Furthermore, we also controlled the influence of
Table 1 Correlation analysis of epidemic risk perception with positive and negative emotions in the three wave investigations

\begin{tabular}{|c|c|c|c|c|c|c|c|c|c|}
\hline & $\begin{array}{l}\text { Risk } \\
\text { perception } \\
\text { T1 }\end{array}$ & $\begin{array}{l}\text { Risk } \\
\text { perception } \\
\text { T2 }\end{array}$ & $\begin{array}{l}\text { Risk } \\
\text { perception } \\
\text { T3 }\end{array}$ & $\begin{array}{l}\text { Positive } \\
\text { emotion } \\
\mathrm{T} 1\end{array}$ & $\begin{array}{l}\text { Positive } \\
\text { emotion } \\
\mathrm{T} 2\end{array}$ & $\begin{array}{l}\text { Positive } \\
\text { emotion } \\
\text { T3 }\end{array}$ & $\begin{array}{l}\text { Negative } \\
\text { emotion } \\
\mathrm{T} 1\end{array}$ & $\begin{array}{l}\text { Negative } \\
\text { emotion } \\
\mathrm{T} 2\end{array}$ & $\begin{array}{l}\text { Negative } \\
\text { emotion } \\
\text { T3 }\end{array}$ \\
\hline 1 & 1 & & & & & & & & \\
\hline 2 & $.57^{* *}$ & 1 & & & & & & & \\
\hline 3 & $.46^{* *}$ & $.58^{* *}$ & 1 & & & & & & \\
\hline 4 & $-.21^{* *}$ & $-.15^{* *}$ & $-.26^{* *}$ & 1 & & & & & \\
\hline 5 & $-.17^{* *}$ & $-.16^{* *}$ & $-.23^{* *}$ & $.65^{* *}$ & 1 & & & & \\
\hline 6 & $-.16^{* *}$ & $-.22^{* *}$ & $-.23^{* *}$ & $.55^{* *}$ & $.71^{* *}$ & 1 & & & \\
\hline 7 & $.22^{* *}$ & $.26^{* *}$ & $.15^{*}$ & $.22^{* *}$ & $.17^{* *}$ & $.17^{* *}$ & 1 & & \\
\hline 8 & $.23^{* *}$ & $.20^{* *}$ & $.16^{* *}$ & $.22^{* *}$ & $.27^{* *}$ & $.31^{* * *}$ & $.63^{* *}$ & 1 & \\
\hline 9 & $.20^{* *}$ & $.13^{*}$ & $.13^{*}$ & $.19^{* * *}$ & $.21^{* *}$ & $.38^{* *}$ & $.49^{* *}$ & $.72^{* *}$ & 1 \\
\hline
\end{tabular}


gender $(1=$ male, $2=$ female $)$ and academic stage $(1=$ junior high middle school, $2=$ senior high middle school, $3=$ university) in the model. The results of the model fitting are presented in the Table 2 .

The results of the cross-lag analysis of epidemic risk perception and positive emotion show that academic stages have a significantly negative prediction $\mathrm{T} 2$ risk perception $(\beta=-0.12, p<0.05)$. Further, the positive emotion at $\mathrm{T} 2$ could negatively predict the risk perception at T3 $(\beta=-0.14$, $p<0.01$ ), and the risk perception at T2 could significantly negatively predict the positive emotion at $\mathrm{T} 3(\beta=-0.11$, $p<0.05)$. However, positive emotions at $\mathrm{T} 1$ could not significantly predict risk perception at $\mathrm{T} 2(\beta=-0.02, p>0.05)$, and the risk perception at $\mathrm{T} 1$ could not significantly predict positive emotions at T2 $(\beta=-0.03, p>0.05)$ (see Fig. 1$)$.

The results of epidemic risk perception and negative emotions shown that the academic stage could positively predict the negative emotions of T2 $(\beta=0.11, p<0.05)$. Further, the negative emotions at $\mathrm{T} 1$ could positively predict the $\mathrm{T} 2$ risk perception $(\beta=0.12, p<0.05)$, and the risk perception at $\mathrm{T} 1$ could significantly positively predict the negative emotion at T2 $(\beta=0.10, p<0.01)$. However, negative emotions at T2 could not significantly predict epidemic risk perception at
$\mathrm{T} 3(\beta=0.05, p>0.05)$, and the epidemic risk perception at $\mathrm{T} 2$ could not significantly predict negative emotions at $\mathrm{T} 3$ $(\beta=-0.01, p>0.05)$ (see Fig. 2).

In summary, after controlling for academic stages and gender, the above results support the hypothesis that risk perception and emotions inter-influence each other. Specifically, for positive emotions, in the time interval between $\mathrm{T} 2$ and T3, positive emotions and risk perceptions show a causal interaction. For negative emotions, in the time interval between $\mathrm{T} 1$ and $\mathrm{T} 2$, negative emotions could positively predict risk perceptions, and at the same time, risk perceptions can also significantly positively predict the negative emotions of individuals.

\section{Multi-group test}

A multi-group comparative structural equation model (SEM) was used to test the cross-lag model difference in terms of gender and academic stages (see Table 3 ). The results show that gender and academic stage caused no significant difference in the relationship between epidemic risk perceptions and positive and negative emotions. This indicates that the above cross-lag results could apply to men and women as
Fig. 1 Cross-lag model of risk perception and positive emotions $* p<0.05 ; * * p<.01$

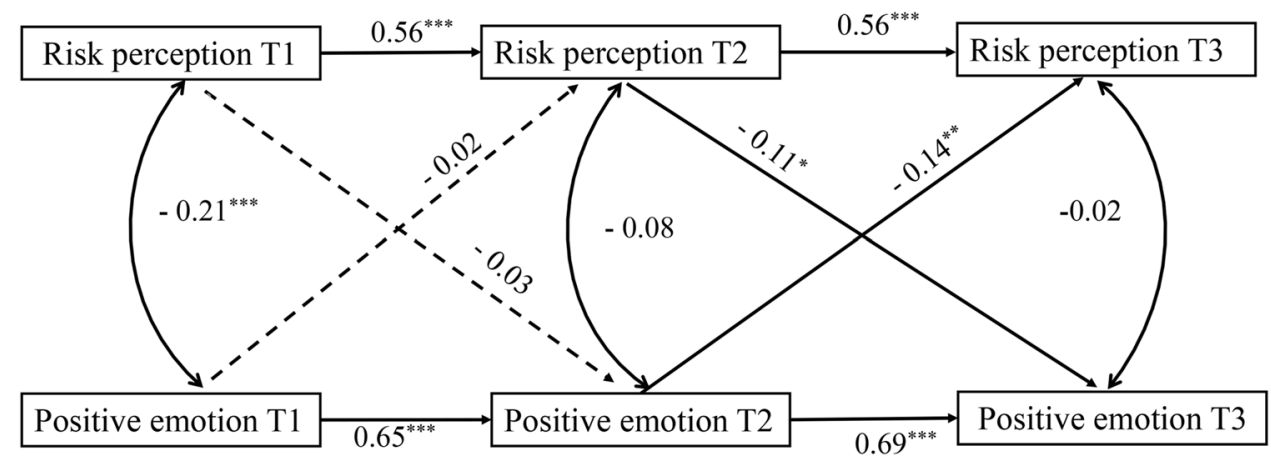

Fig. 2 Cross-lag model of risk perception and negative emotions $* p<0.05 ; * * p<.01$

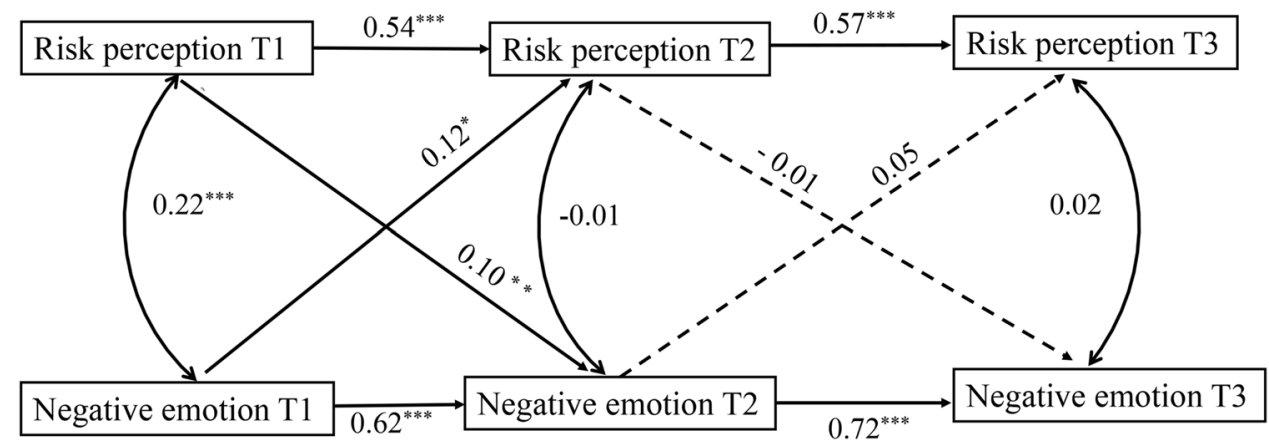

Table2 Model fitting indicators 
Table 3 Comparison of the difference in the cross-lag model in terms of gender and college stages

\begin{tabular}{|c|c|c|c|c|c|c|c|c|c|c|}
\hline & \multirow[b]{2}{*}{ Model } & \multicolumn{5}{|c|}{ Model fit } & \multicolumn{4}{|c|}{ Model comparison } \\
\hline & & $\overline{\chi^{2}}$ & $d f$ & CFI & TLI & $\overline{\text { RMSEA }}$ & Model & $\Delta \chi^{2}$ & $\Delta d f$ & $p$ \\
\hline \multirow[t]{6}{*}{ Gender } & Positive emotion & & & & & & & & & \\
\hline & M1: Unconstrained model & 21.28 & 8 & 0.97 & 0.90 & 0.11 & M2-M1 & 0.75 & 4 & 0.95 \\
\hline & M2: Constrained model & 22.21 & 12 & 0.98 & 0.95 & 0.08 & & & & \\
\hline & Negative emotion & & & & & & & & & \\
\hline & M1: Unconstrained model & 17.20 & 8 & 0.98 & 0.93 & 0.09 & M2-M1 & 3.80 & 4 & 0.43 \\
\hline & M2: Constrained model & 20.66 & 12 & 0.98 & 0.95 & 0.07 & & & & \\
\hline \multirow[t]{6}{*}{ School } & Positive emotion & & & & & & & & & \\
\hline & M1: Unconstrained model & 27.12 & 12 & 0.98 & 0.90 & 0.11 & M2-M1 & 13.64 & 8 & 0.09 \\
\hline & M2: Constrained model & 41.92 & 20 & 0.96 & 0.91 & 0.10 & & & & \\
\hline & Negative emotion & & & & & & & & & \\
\hline & M1: Unconstrained model & 22.20 & 12 & 0.98 & 0.93 & 0.09 & M2-M1 & 7.71 & 8 & 0.46 \\
\hline & M2: Constrained model & 29.02 & 20 & 0.98 & 0.96 & 0.07 & & & & \\
\hline
\end{tabular}

well as to college, senior high middle school, and junior high middle school students.

\section{Discussion}

This study used Chinese adolescent students in different academic stages as participants and explored the relationship between the perceived risk of the epidemic and emotions during home quarantine in the early stages of COVID-19. Using the self-compiled epidemic risk perception questionnaire and Watson's PANAS with good reliability and validity, through three consecutive follow-up surveys, it was found that epidemic risk perception and negative emotions are significantly positively correlate. This is consistent with the results of Li et al. (2020b) on the general public and Zhong et al. (2020) on people infected with COVID-19. However, current study further found that there is a causal relationship between epidemic risk perception and negative emotions in the short term. In addition, during the outbreak of public health incidents, existing research mainly focuses on the relationship between negative emotions and risk perception (Yang \& Chu, 2016). Current study also found that there is still a causal relationship between adolescents' positive emotions and risk perceptions, and the individual's positive emotions were significantly higher than their negative emotions at $\mathrm{T} 1, \mathrm{~T} 2$, and $\mathrm{T} 3$.

The current study found that the individual's positive emotions were significantly higher than the negative emotions at T1, T2, and T3. This result is different from previous research during public health events. For example, studies have found that during the SARS outbreak, disgust, loneliness, and depression were the most common emotional experiences of quarantined individuals (Cava et al., 2005; Reynolds et al., 2007). Tausczik et al. (2012) found that $\mathrm{H} 1 \mathrm{~N} 1$ can cause public anxiety, and even during the
COVID-19 pandemic, studies have shown that individuals have negative psychological experiences such as depression and stress (Wang et al., 2020; Yan et al., 2021). This difference may be due to the different research samples. In a study of participants infected with COVID-19 (Zhong et al., 2020) and medical staff (Y1ldrım et al., 2020), because individuals are at the center of the epidemic or on the front line of epidemic prevention and control, they could experience huge risk of infection and easily produce negative emotions such as anxiety and depression. However, this study does not include participants of Wuhan, and the individuals are far away from the areas where the epidemic was most severe at that time. In addition, previous studies have mostly used adults as participants, the economic downward pressure on families in quarantine and the lack of a stable source of income resulted in acute psychological pressure and negative emotions during the period of home quarantine (Brooks et al., 2020). The main task of adolescents' students is to learn, and they experience little economic stress. Therefore, adolescent individuals show less negative emotions and more positive emotions.

The results of the cross-lag indicate that there is an interaction between emotions and perceptions of epidemic risk. For positive emotions, there is a significantly negative correlation between the positive emotions experienced by individuals and their risk perception, and the risk perceptions at T2 can negatively predict the positive emotions at T3. At the same time, the positive emotions at T2 could also negatively predict the individual's T3 epidemic risk perception. Adolescent individuals' positive emotions, apart from their not having to bear any economic pressure, are also related to the state and government's successful prevention and control of the epidemic. At the end of January 2020 right before the current survey commenced, the Chinese government has actively adopted a variety of measures to control COVID19, including implementing effective medical treatment, 
monitoring the progress, issuing factsheets and precautionary guidelines, and even controlling the mobility of population within the city and between city.

Therefore, although the majority of adolescents realize that the epidemic of COVID-19 is harmful, it is also controllable and curable. Previous studies have also found that positive information, such as government's active preventive measures, could reduce the individual's risk perception level (Terpstra, 2011) and help to alleviate the individual's negative emotional state. In addition, research has found that positive emotions can help reduce risk propensity under the framework of loss (Cassotti et al., 2012), and they can cause the individual to show a more optimistic risk assessment ( $\mathrm{Au}$ et al., 2003; Johnson \& Tversky, 1983; Lin et al., 2006). As a result, there is a causal relationship between epidemic risk perceptions and positive emotions.

Negative emotions are positively correlated with epidemic risk perceptions, and there is a causal relationship between risk perception and negative emotions in $\mathrm{T} 1$ and $\mathrm{T} 2$. Due to the strong spread of COVID-19, the public deeply realizes the degree of its harm. These risk perceptions of COVID-19, coupled with the government's requirement to adopt a home quarantine strategy to prevent the epidemic, have inevitably caused individuals to become anxious, panicked, and even depressed (Duan et al., 2020). These relatively negative emotions continue to prompt individuals to pay attention to the risks of the epidemic, which has created an interactive relationship between negative emotions and risk perception. For example, Zhong et al. (2020) found that there is a significant positive correlation between risk perception and negative emotions. Similarly, Yang and Chu (2016) found that during the Ebola epidemic, individual negative emotions, such as fear and anxiety, were positively correlated with risk perception.

This study provides an inspiration to promote adolescent mental health during public health event. Based on the casual relationship between risk perception and emotions, on the one hand, the risk perceptions of an epidemic could increase the individual's negative emotions and decrease his or her positive experiences. Therefore, increasing positive reports about the effectiveness of epidemic control, and having some knowledge of epidemic prevention measures (Kim $\&$ Choi, 2016) can help reduce adolescents' risk perception and increase their confidence about success of the battle against the epidemic, then reducing negative emotions. In addition, poor physical condition could lead to increasing the individual's risk perception of the epidemic, then resulting in anxiety and depression of the individual. Therefore, maintaining good health and obtaining health-related diagnosis information in time when the individual feels bad could reduce the trouble caused by suspected symptoms, reducing the impact of the epidemic, and then increasing the positive experience of individuals (Wang et al., 2021a). On the other hand, negative emotions are also likely to increase the individual's risk perception. Therefore, by means such as family companionship (White \& Dolan, 2009) and parents communicating with their children (Dalton et al., 2020) could help individuals reduce panic and promote scientific epidemic prevention. More importantly, adolescents' positive emotional experience is higher than negative emotions, and there is a causal relationship between positive emotions and epidemic risk perception. Therefore, besides eliminating negative emotions, it is necessary to further guide and maintain the positive emotions of adolescents. This is also an effective way to decrease the impact of epidemic on adolescents.

With the improvement of mobile phone functions, adolescents are among the heaviest mobile phone users, which provides opportunities for adolescents to participate in mobile health interventions (Zhang et al., 2021). The study found that a low proportion use health-related mobile phone apps, but a high level of receptiveness and satisfaction among youth (Do et al., 2018; Tran et al., 2018). Actively carrying out online psychological counseling cold help eliminate the impact of geographical distance which individuals might need to travel in order to receive such form of therapy previously, and improving the mental health of adolescents (Ho et al., 2020; Zhang \& Ho, 2017). Research found that Internet cognitive behavioral therapy could effectively improve individual sleep quality (Soh et al., 2020) and relieve psychological stress (Sijbrandij et al., 2016). For rural areas with low coverage of networks and limited health resources, in order to decrease negative experience of individuals, it is possible to help adolescents master the knowledge and psychological counseling skills related to epidemic prevention and control by printing and distributing training materials and recording and broadcasting (Tran, et al., 2020).

In this study, adolescents at different academic stages who were quarantined at home in the early stage of the COVID19 were selected as the participants, and data with high ecological validity was used to not only verify the correlation between risk perception and negative emotions found in previous studies (Li et al., 2020b; Yang \& Chu, 2016; Zhong et al., 2020), but also further found that there is a causal relationship between risk perception with positive and negative emotions in public health events. In addition, this study also found that gender and age did not affect the causal relationship between risk perception and emotion of adolescents. This is a deepening and supplement to previous studies (Li et al., 2020b; Zhong et al., 2020) that only found a significant positive correlation between risk perception and negative emotions. However, despite this study having the above advantages, there still remain some limitations. First, the sample size of the study was limited, and more adolescents could not be investigated in the study. Second, this study only conducted a short-term tracking investigation 
at the early stage of the COVID-19 epidemic, and it did not carry longer-term continuous tracking. These issues need to be compared and analyzed with other similar studies to explored in future research.

\section{Conclusion}

This study explored the relationship between adolescents' perception of epidemic risk and emotions, and found that in the early stage of COVID-19, the adolescents' positive emotions were higher than negative emotions, and there was an interactive relationship between epidemic risk perception with positive and negative emotions. In addition, the results of cross-lag are no difference between gender and academic stage. Current study has the great significance for the emotional management and risk reduction of adolescents' during similar public health events in the future. Specifically, during the period of home quarantine, in order to effectively improve the mental health of adolescents, on the one hand, it is possible to increase the positive emotions of individuals and reduce the negative emotional experience by reducing the epidemic risk perception in time. On the other hand, guiding and maintaining the positive emotions of adolescents or reducing the negative emotions could also decrease the epidemic risk perceptions of individuals.

Funding This research did not receive any specific grant from funding agencies in the public, commercial, or not-for-profit sectors.

Data Availability The datasets generated during and/or analysed during the current study are available from the corresponding author on reasonable request.

\section{Declarations}

Conflicts of Interest/Competing Interests The authors have no conflicts of interest to declare.

Informed Consent Informed consent was obtained from all participants in the study.

\section{References}

Arnett, J. J. (1999). Adolescent storm and stress, reconsidered. American Psychologist, 54(5), 317-326. https://doi.org/10.1037/0003066X.54.5.317

Au, K., Chan, F., Wang, D., \& Vertinsky, I. (2003). Mood in foreign exchange trading: Cognitive processes and performance. Organizational Behavior \& Human Decision Processes, 91(2), 322-338. https://doi.org/10.1016/S0749-5978(02)00510-1

Blakemore, S. J., \& Robbins, T. W. (2012). Decision-making in the adolescent brain. Nature Neuroscience, 15(9), 1184-1191. https:// doi.org/10.1038/nn.3177
Blakey, S. M., Reuman, L., Jacoby, R. J., \& Abramowitz, J. S. (2015). Tracing "Fearbola": Psychological predictors of anxious responding to the threat of Ebola. Cognitive. Therapy Research, 39(6), 816-825. https://doi.org/10.1007/s10608-015-9701-9

Brooks, S. K., Webster, R. K., Smith, L. E., Woodland, L., Wessely, S., Greenberg, N., \& Rubin, G. J. (2020). The psychological impact of quarantine and how to reduce it: Rapid review of the evidence. Lancet (london, England), 395(10227), 912-920. https://doi.org/ 10.1016/S0140-6736(20)30460-8

Cassotti, M., Habib, M., Poirel, N., AÏte, A., Houdé, O., \& Moutier, S. (2012). Positive emotional context eliminates the framing effect in decision-making. Emotion, 12(5), 926-931. https://doi.org/10. $1037 / \mathrm{a} 0026788$

Carstensen, L. L., Shavit, Y. Z., \& Barnes, J. T. (2020). Age advantages in emotional experience persist even under threat from the COVID-19 pandemic. Psychological Science, 31(11), 1374-1385. https://doi.org/10.1177/0956797620967261

Cava, M. A., Fay, K. E., Beanlands, H. J., Mccay, E. A., \& Wignall, R. (2005). The experience of quarantine for individuals affected by SARS in Toronto. Public Health Nursing, 22(5), 398-406. https:// doi.org/10.1111/j.0737-1209.2005.220504.x

Charles, N. E., Strong, S. J., Burns, L. C., Bullerjahn, M. R., \& Serafine, K. M. (2021). Increased mood disorder symptoms, perceived stress, and alcohol use among college students during the COVID-19 pandemic. Psychiatry Research, 296, 113706. https:// doi.org/10.1016/j.psychres.2021.113706

Cowling, B. J., Ng, D. M. W., Ip, D. K. M., Liao, Q., Lam, W. W. T., Wu, J. T., Lau, J. F. T., Griffiths, S. M., \& Fielding, R. (2010). Community psychological and behavioral responses through the first wave of the 2009 Influenza A(H1N1) Pandemic in Hong Kong. The Journal of Infectious Diseases, 202(6), 867-876. https://doi.org/10.1086/655811

Cui, Y., Li, F., Leckman, J. F., Guo, L., Ke, X., Liu, J., Zheng, Y., \& Li, Y. (2020). The prevalence of behavioral and emotional problems among Chinese school children and adolescents aged 6-16: A national survey. European Child \& Adolescent Psychiatry, 30, 233-241. https://doi.org/10.1007/s00787-020-01507-6

Dalton, L., Rapa, E., \& Stein, A. (2020). Protecting the psychological health of children through effective communication about COVID-19. The Lancet Child \& Adolescent Health, 4(5), 346347. https://doi.org/10.1016/S2352-4642(20)30097-3

Do, T. T. T., Le, M. D., Van Nguyen, T., Tran, B. X., Le, H. T., Nguyen, H. D., Nguyen, L. H., Nguyen, C. T., Tran, T. D., Latkin, C. A., Ho, R. C. M., \& Zhang, M. W. B. (2018). Receptiveness and preferences of health-related smartphone applications among Vietnamese youth and young adults. BMC Public Health, 18(1), 764. https://doi.org/10.1186/s1288.9-018-5641-0

Duan, H., Yan, L., Ding, X., \& G, Y., Kohn, N., \& Wu, J. (2020). Impact of the COVID-19 pandemic on mental health in the general Chinese population: Changes, predictors and psychosocial correlates. Psychiatry Research, 293, 113396. https://doi.org/10. 1016/j.psychres.2020.113396

Frala, J. L., Leen-Feldner, E. W., Blumenthal, H., \& Barreto, C. C. (2010). Relations among perceived control over anxiety-related events, worry, and generalized anxiety disorder in a sample of adolescents. Journal of Abnormal Child Psychology, 38(2), 237247. https://doi.org/10.1007/s10802-009-9365-6

Gerhold, L. (2020). COVID-19: Risk perception and Coping strategies. Results from a survey in Germany. https://doi.org/10.31234/osf. io/xmpk4

Haase, C. M., \& Silbereisen, R. K. (2011). Effects of positive affect on risk perceptions in adolescence and young adulthood. Journal of Adolescence, 34(1), 29-37. https://doi.org/10.1016/j.adolescence. 2010.03.004

Ho, C. S., Chee, C. Y., \& Ho, R. C. (2020). Mental health strategies to combat the psychological impact of COVID-19 beyond paranoia 
and panic. Annals of the Academy of Medicine, Singapore, 49(1), 1-3. https://doi.org/10.47102/annals-acadmedsg.202043

Hu, T. Y., Xie, X., \& Jie, L. (2013). Negative or positive? the effect of emotion and mood on risky driving. Transportation Research Part f: Traffic Psychology and Behaviour, 16, 29-40. https://doi. org/10.1016/j.trf.2012.08.009

Johnson, E. J., \& Tversky, A. (1983). Affect, generalization, and the perception of risk. Journal of Personality and Social Psychology, 45(1), 20-31. https://doi.org/10.1037/0022-3514.45.1.20

Kecojevic, A., Basch, C. H., Sullivan, M., \& Davi, N. K. (2020). The impact of the COVID-19 epidemic on mental health of undergraduate students in New Jersey, cross-sectional study. PLoS ONE, 15, e0239696. https://doi.org/10.1371/journal.pone.0239696

Kim, J. S., \& Choi, J. S. (2016). Middle East respiratory syndromerelated knowledge, preventive behaviours and risk perception among nursing students during out- break. Journal of Clinical Nursing, 25(17-18), 2542-2549. https://doi.org/10.1111/jocn. 13295

Lee, Y., Lui, L. M. W., Chen-Li, D., Liao, Y., Mansur, R. B., Brietzke, E., Rosenblat, J. D., Ho, R., Rodrigues, N. B., Lipsitz, O., Nasri, F., Cao, B., Subramaniapillai, M., Gill, H., Lu, C., \& McIntyre, R. S. (2021). Government response moderates the mental health impact of COVID-19: A systematic review and meta-analysis of depression outcomes across countries. Journal of Affect Disorders, 290, 364-377. https://doi.org/10.1016/J.JAD.2021.04.050

Lerner, J. S., Gonzalez, R. M., Small, D. A., \& Fischhoff, B. (2010). Effects of fear and anger on perceived risks of terrorism a national field experiment. Psychological Science, 14(2), 144-150. https:// doi.org/10.1111/1467-9280.01433

Li, H. Y., Cao, H., Leung, D. Y. P., \& Mak, Y. W. (2020a). The psychological impacts of a COVID-19 outbreak on college students in China: A longitudinal study. International Journal of Environmental Research and Public Health, 17(11), 3933. https://doi.org/ 10.3390/ijerph17113933

Li, J., Yang, A., Dou, K., Wang, L., Zhang, M., \& Lin, X. (2020b). Chinese public's knowledge, perceived severity, and perceived controllability of COVID-19 and their associations with emotional and behavioural reactions, social participation, and precautionary behavior: A national survey. BCM Public Health, 20, 1589. https://doi.org/10.1186/s12889-020-09695-1

Li, Y., Luan, S., Li, Y., \& Hertwig, R. (2021). Changing emotions in the COVID-19 pandemic: A four-wave longitudinal study in the United States and China. Social Science \& Medicine, 285, 114222. https://doi.org/10.1016/j.socscimed.2021.114222

Liang, Z., Mazzeschi, C., \& Delvecchio, E. (2021). The Impact of Parental Stress on Italian Adolescents' Internalizing Symptoms during the COVID-19 Pandemic: A Longitudinal Study. International Journal of Environmental Research and Public Health, 18(15), 8074. https://doi.org/10.3390/ijerph18158074

Lin, C. -H., Yen, H. R., \& Chuang, S. -C. (2006). The effects of emotion and need for cognition on consumer choice involving risk. Marketing Letters, 17(1), 47-60. https://doi.org/10.1007/ s11002-006-4146-2

van der Linden, S. (2014). On the relationship between personal experience, affect and risk perception: The case of climate change. European Journal of Social Psychology, 44(5), 430-440. https:// doi.org/10.1002/ejsp.2008

Liu, N., Zhang, F., Wei, C., Jia, Y., Shang, Z., Sun, L., Wu, L., Sun, Z., Zhou, Y., Wang, Y., \& Liu, W. (2020). Prevalence and predictors of PTSS during COVID-19 outbreak in China hardest-hit areas: Gender differences matter. Psychiatry Research, 287, 11921. https://doi.org/10.1016/j.psychres.2020.112921

Nan, X. (2016). Influence of incidental discrete emotions on health risk perception and persuasion. Health Communication, 32(6), 721-729. https://doi.org/10.1080/10410236.2016.1168004
Martinelli, N., Gil, S., Belletier, C., Chevalère, J., Dezecache, G., Huguet, P., \& Droit-Volet, S. (2020). Time and emotion during lockdown and the Covid-19 epidemic: determinants of our experience of time? Frontiers in Psychology, 11. https://doi.org/ 10.3389/fpsyg.2020.616169

Muris, P. (2002). Relationships between self-efficacy and symptoms of anxiety disorders and depression in a normal adolescent sample. Personality \& Individual Differences, 32(2), 337-348. https://doi.org/10.1016/S0191-8869(01)00027-7

Pechmann, C., Levine, L., Loughlin, S., \& Leslie, F. (2005). Impulsive and self-conscious: Adolescents' vulnerability to advertising and promotion. Journal of Public Policy \& Marketing, 24(2), 202-221. https://doi.org/10.1509/jppm.2005.24.2.202

Ren, Z., Xin, Y., Wang, Z., Liu, D., Ho, R. C. M., \& Ho, C. S. H. (2021). What Factors Are Most Closely Associated with Mood Disorders in Adolescents During the COVID-19 Pandemic? A Cross-Sectional Study Based on 1,771 Adolescents in Shandong Province. China. Frontiers in Psychiatry, 12, 728278. https:// doi.org/10.3389/fpsyt.2021.728278

Reynolds, D. L., Garay, J. R., Deamond, S. L., Moran, M. K., Gold, W., \& Styra, R. (2007). Understanding, compliance and psychological impact of the SARS quarantine experience. Epidemiology \& Infection, 136(7), 997-1007. https://doi.org/10.1017/ S0950268807009156

Riaz, M., Abid, M., \& Bano, Z. (2021). Psychological problems in general population during covid-19 pandemic in Pakistan: Role of cognitive emotion regulation. Annals of Medicine, 53(1), 189-196. https://doi.org/10.1080/07853890.2020.1853216

Shorer, M., \& Leibovich, L. (2020). Young children's emotional stress reactions during the COVID-19 outbreak and their associations with parental emotion regulation and parental playfulness. Early Child Development and Care, 1-11. https://doi.org/ 10.1080/03004430.2020.1806830

Siddiqui, S. (2015). Impact of self-efficacy on psychological wellbeing among undergraduate students. The International Journal of Indian Psychology, 2(3), 5-16.

Sijbrandij, M., Kunovski, I., \& Cuijpers, P. (2016). Effectiveness of internet-delivered cognitive behavioral therapy for posttraumatic stress disorder: A systematic review and meta-analysis. Depression and Anxiety, 33(9), 783-791. https://doi.org/10. 1002/da.22533

Slovic, P. (2000). Perception of risk. In P. Slovic (Ed.), The perception of risk (pp. 220-231). Earthscan.

Sjöberg, L. (2007). Emotions and risk perception. Risk Management, 9(4), 223-237. https://doi.org/10.1057/palgrave.rm.8250038

Soltan, E. M., El-Zoghby, S. M., \& Salama, H. M. (2020). Knowledge, risk perception, and preventive behaviors related to COVID-19 pandemic among undergraduate medical students in Egypt. SN Comprehensive Clinical Medicine, 2(12), 25682575. https://doi.org/10.1007/s42399-020-00640-2

Soh, H. L., Ho, R. C., Ho, C. S., \& Tam, W. W. (2020). Efficacy of digital cognitive behavioural therapy for insomnia: A metaanalysis of randomised controlled trials. Sleep Medicine, 75, 315-325. https://doi.org/10.1016/j.sleep.2020.08.020

Spagnolo, P. A., Manson, J. E., \& Joffe, H. (2020). Sex and gender differences in health: What the COVID-19 pandemic can teach US. Annals of Internal Medicine, 173(5), 385-386. https://doi. org/10.7326/M20-1941

Tausczik, Y., Faasse, K., Pennebaker, J. W., \& Petrie, K. J. (2012). Public anxiety and information seeking following the H1N1 outbreak: Blogs, newspaper articles, and Wikipedia visits. Health Communication, 27(2), 179-185. https://doi.org/10.1080/10410 236.2011.571759

Terpstra, T. (2011). Emotions, trust, and perceived risk: Affective and cognitive routes to flood preparedness behavior. Risk 
Analysis, 31(10), 1658-1675. https://doi.org/10.1111/j.15396924.2011.01616.x

Tran, B. X., Zhang, M. W., Le, H. T., Nguyen, H. D., Nguyen, L. H., Nguyen, Q. L. T., Tran, T. D., Latkin, C. A., \& Ho, R. C. (2018). What drives young Vietnamese to use mobile health innovations? implications for health communication and behavioral interventions. JMIR Mhealth Uhealth, 6(11), e194. http://mhealth.jmir. org/2018/11/e194/

Tran, B. X., Phan, H. T., Nguyen, T. P. T., Hoang, M. T., Vu, G. T., Lei, H. T., Latkin, C. A., Ho, C. S., \& Ho, R. C. (2020). Reaching further by village health collaborators: the informal health taskforce of Vietnam for COVID-19 responses. Journal of global health, 10(1), 010354. https://doi.org/10.7189/jogh.10.010354

Wang, C., Pan, R., Wan, X., Tan, Y., Xu, L., Ho, C. S., \& Ho, R. C. (2020). Immediate psychological responses and associated factors during the initial stage of the 2019 coronavirus disease (COVID19) epidemic among the general population in China. International Journal of Environmental Research and Public Health, 17(5), 1729. https://doi.org/10.3390/ijerph17051729

Wang, C., Chudzicka-Czupała, A., Tee, M. L., Núñez, M. I. L., Tripp, C., Fardin, M. A., Habib, H. A., Tran, B. X., Adamus, K., Anlacan, J., Garcia, M. E. A., Grabowski, D., Hussain, S., Hoang, M. T., Hetnal, M., Le, X. T., Ma, W., Pham, H. Q., Reyes, P. W., \& C.,... Sears, S. F. (2021a). A chain mediation model on COVID19 symptoms and mental health outcomes in Americans. Asians and Europeans. Scientific Reports, 11(1), 6481. https://doi.org/ 10.1038/s41598-021-85943-7

Wang, C., Tee, M., Roy, A. E., Fardin, M. A., Srichokchatchawan, W., Habib, H. A., Tran, B. X., Hussain, S., Hoang, M. T., Le, X. T., Ma, W., Pham, H. Q., Shirazi, M., Taneepanichskul, N., Tan, Y., Tee, C., Xu, L., Xu, Z., Vu, G., T.,...Kuruchittham, V., et al. (2021b). The impact of COVID-19 pandemic on physical and mental health of Asians: A study of seven middle- income countries in Asia. PLoS ONE, 16(2), e0246824. https://doi.org/ 10.1371/journal.pone.0246824

Wang, Y., Xu, B., Zhao, G., Cao, R., He, X., \& Fu, S. (2011). Is quarantine related to immediate negative psychological consequences during the 2009 H1N1 epidemic? General Hospital Psychiatry, 33(1), 75-77. https://doi.org/10.1016/j.genhosppsych.2010.11.001

Watson, D., Clark, L. A., \& Tellegen, A. (1988). Development and validation of brief measures of positive and negative affect: The PANAS scales. Journal of Personality and Social Psychology, 54(6), 1063-1070. https://doi.org/10.1037/0022-3514.54.6.1063

World Health Organization. (2020a). WHO Director-General's statement on IHR Emergency Committee on Novel Coronavirus(2019nCoV). https://www.who.int/director-general/speeches/detail/ who-director-general-s-statement-on-ihr-emergency-committeeon-novel-coronavirus-(2019-ncov). Accessed 12 Jan 2021

World Health Organization. (2020b). WHO Director-General's opening remarks at the media briefing on COVID-19- 11 March 2020. https://www.who.int/director-general/speeches/detail/ who-director-general-s-opening-remarks-at-the-media-briefingon-covid-19---11-march-2020. Accessed 12 Jan 2021.

World Health Organization. (2020c). WHO Coronavirus disease 2019 (COVID-19) situation report-100. 29-April-2020. URL: https:// www.who.int/docs/default-source/coronaviruse/situation-reports/ 20200429-sitrep-100-covid-19.pdf?sfvrsn=bbfbf3d1_2. Accessed 12 Jan 2021

White, M. P., \& Dolan, P. (2009). Accounting for the richness of daily activities. Psychological Science, 20, 1000-1008. https://doi.org/ 10.1111/j.1467-9280.2009.02392.x

Xiong, J., Lipsitz, O., Nasri, F., Lui, L. M. W., Gill, H., Phan, L., Chen-Li, D., Iacobucci, M., Ho, R., Majeed, A., \& Mclntyre, R. S. (2020). Impact of COVID-19 pandemic on mental health in the general population: A systematic review. Journal of Affective Disorders., 277, 55-64. https://doi.org/10.1016/j.jad.2020.08.001

Yan, L., Gan, Y., Ding, X., Wu, J., \& Duan, H. (2021). The relationship between perceived stress and emotional distress during the COVID-19 outbreak: effects of boredom proneness and coping style. Journal of Anxiety Disorders, 77. https://doi.org/10.1016/j. janxdis.2020.102328

Yang, J., \& Chu, H. (2016). Who is afraid of the Ebola outbreak? the influence of discrete emotions on risk perception. Journal of Risk Research, 21(7), 1-20. https://doi.org/10.1080/13669877.2016. 1247378

Yang, X., Gong, R., Sassine, S., Morsa, M., Tchogna, A. S., Drouin, O., Chadi, N., \& Jantchou, P. (2020). Risk perception of COVID-19 infection and adherence to preventive measures among adolescents and young adults. Children, 7(12), 311. https://doi.org/10. 3390/children7120311

Yıldırım, M., Arslan, G. \& Özaslan, A. (2020). Perceived risk and mental health problems among healthcare professionals during COVID-19 pandemic: exploring the mediating effects of resilience and coronavirus fear. International Journal of Mental Health and Addiction, 1-25. https://doi.org/10.31234/osf.io/84xju

Yıldırım, M., \& Özaslan, A. (2021). Worry, severity, controllability, and preventive behaviours of COVID-19 and their associations with mental health of Turkish healthcare workers working at a pandemic hospital. International Journal of Mental Health and Addiction, 4, 1-15. https://doi.org/10.1007/s11469-021-00515-0

Zhang, M. W., \& Ho, R. C. (2017). Moodle: The cost effective solution for internet cognitive behavioral therapy (I-CBT) interventions. Technology and Health Care, 25(1), 163-165. https://doi.org/10. 3233/THC-161261

Zhang, M. W. B, Chow, A., Ho, R. C. M., \& Smith, H. E. (2021). An Overview of Commercially Available Apps in the Initial Months of the COVID-19 Pandemic. Frontiers in Psychiatry, 12, https:// doi.org/10.3389/fpsyt.2021.557299

Zhang, S. P. (2006). Mental health. In S. P. Zhang (Ed.), Children's survival anddevelopment in China: Data and analysis (pp. 154-157). China Women Publishing House.

Zhong, Y., Liu, W., Lee, T., Zhao, H., \& Ji, J. (2020). Risk perception, knowledge, information sources and emotional states among COVID-19 patients in Wuhan, China: A cross-sectional survey. Nursing Outlook. https://doi.org/10.1016/j.outlook.2020.08.005

Publisher's Note Springer Nature remains neutral with regard to jurisdictional claims in published maps and institutional affiliations. 